\title{
ASO Author Reflections: What is the Most Reasonable Approach to Abdominoperineal Resection for Low Rectal Cancer?
}

\author{
Takeru Matsuda, $\mathrm{MD}, \mathbf{P h D}^{1,2}$ \\ ${ }^{1}$ Division of Gastrointestinal Surgery, Department of Surgery, Kobe University Graduate School of Medicine, Kobe, Japan; \\ ${ }^{2}$ Division of Minimally Invasive Surgery, Department of Surgery, Kobe University Graduate School of Medicine, Kobe, \\ Japan
}

\section{PAST}

Although laparoscopic surgery has been utilized worldwide for colorectal cancer surgery, abdominoperineal resection (APR) is still technically demanding. It was also reported that oncological outcomes were inferior in APR than in low anterior resection. ${ }^{1}$ Such worse outcomes most likely resulted from difficult surgical procedures in the deep pelvis, even when utilizing the abdominal laparoscopic approach. Furthermore, a large perineal incision and long operative time would also play a part in increasing the complications after APR.

\section{PRESENT}

Recently, transanal total mesorectal excision (TaTME) has been introduced as an innovative procedure for mid and low rectal cancer. Although TaTME could be a promising approach for APR because of easy access to the deep pelvis and the two-team approach, it includes unique problems such as urethral injury and difficult anatomy. In particular, urethral injury is a serious problem when TaTME is performed for low rectal tumors located at or below the anorectal ring, such as intersphincteric resection and APR. ${ }^{2}$ Therefore, standardization of the TaTME procedure for APR is required. In our procedure, the operative procedure was divided into seven steps. ${ }^{3}$ By following these steps,

(C) Society of Surgical Oncology 2021

First Received: 14 December 2021

Accepted: 14 December 2021;

Published Online: 10 January 2022

T. Matsuda, $\mathrm{MD}, \mathrm{PhD}$

e-mail: takerumatsuda@nifty.com transperineal minimally invasive APR can be performed safely. The most important concept during this procedure is the sufficient division of the puborectalis sling, resulting in identification of the prostate.

\section{FUTURE}

Currently, the transanal minimally invasive approach seems to be unpopular for APR because of its technical difficulty. Following these steps and understanding the anatomical structures surrounding the anorectal ring from the perineal view would help with the safe introduction of this surgery. However, most importantly, oncological outcomes need to be evaluated in the near future.

DISCLOSURE Takeru Matsuda has no conflicts of interest to disclose.

\section{REFERENCES}

1. Wibe A, Syse A, Andersen E, Tretli S, Myrvold HE, Søreide O. Oncological outcomes after total mesorectal excision for cure for cancer of the lower rectum: anterior vs. abdominoperineal resection. Dis Colon Rectum. 2004;47:48-58.

2. Sylla P, Knol JJ, D'Andrea AP, et al. Urethral injury and other urologic injuries during transanal total mesorectal excision: an international collaborative study. Ann Surg. 2021;274(2):e115-25.

3. Matsuda T, Sawada R, Hasegawa H. Standardized procedure of transperineal minimally invasive abdominoperineal resection for low rectal cancer. Ann Surg Oncol. 2021. https://doi.org/10.1245/ s10434-021-11214-4.

Publisher's Note Springer Nature remains neutral with regard to jurisdictional claims in published maps and institutional affiliations. 